\title{
21
}

\section{PRINCIPIOS GENERALES PARA UNA NUEVA NORMATIVA DE ACCESO A LA INFORMACIÓN PÚBLICA.}

Lilian Molina, Guillermo Santa María, Arturo Clery. 


\title{
Principios generales para una nueva normativa de acceso a la información pública \\ GENERAL PRINCIPLES FOR A NEW RULES ON ACCESS WING PUBLIC INFORMATION
}

\author{
Lilian Molina; Guillermo Santa María; Arturo Clery \\ Universidad Estatal Península de Santa Elena (UPSE) \\ Campus La Libertad, vía principal Santa Elena - La Libertad \\ La Libertad-Ecuador \\ lmolina@upse.edu.ec ${ }^{(1)}$
}

\begin{abstract}
Resumen
El derecho de la información ha sido descrito por los estudiosos del tema y la doctrina como un modo especial de manifestación del hombre, que es la comunicación, forma natural de relación, individual o social, que el derecho acota para elevarla a la categoría de relaciones jurídicas; por lo que el derecho de la información deriva del derecho que el hombre tiene de manifestarse con los demás y parte de la necesidad natural de interactuar con el grupo al que pertenece. El derecho de la información ha sido considerado como el conjunto de normas jurídicas que tienen por objeto la tutela, reglamentación y delimitación del derecho a obtener y difundir ideas, opiniones y hechos con carácter de noticiables, es decir, con trascendencia pública; es el conjunto de normas jurídicas aplicables al proceso informativo, lo que incluye entre otros elementos al régimen jurídico de los medios de comunicación, al estatuto profesional de los comunicadores, a los derechos de autor de quienes generan información, etc. El derecho de la información representa la rama del Derecho que comprende el conjunto de normas jurídicas reguladoras de la actividad informativa y de la tutela efectiva del derecho a las libertades de información, en la forma en que se reconocen y quedan constitucionalmente establecidas.
\end{abstract}

Palabras Claves: derecho, acceso, información, ley, comunicación.

\begin{abstract}
The right of information has been described by scholars and doctrine as a special mode of manifestation of man, which is communication, natural form of relationship, individual or social, that the right narrows to raise it to the category of relationship legal; so the right to information derived from the right that man has to manifest itself with others and part of the natural need to interact with the group to which it belongs. The right of information has been considered as the set of legal rules aimed at the protection, regulation and delimitation of the right to obtain and disseminate ideas, opinions and facts with character noticiables, ie, with public significance; is the set of legal rules applicable to the reporting process, including inter alia the legal status of the media, the professional status of journalists, to the copyright of those who generate information, etc.. The right of information represents the branch of law that covers all the legal rules governing the transmission of information and the effective protection of the right to freedom of information, how they are recognized and are constitutionally established.
\end{abstract}

Keywords: right, access, information, law, communication.

\section{Introducción}

El derecho de la información es una forma especial de manifestación de las ideas, opiniones y hechos con trascendencia pública; comprende un conjunto de ordenamientos jurídicos que regulan todo el proceso informativo, desde la creación de los medios de información, las obligaciones de los sujetos activos y pasivos, la tutela del derecho y por supuesto los límites al derecho (Hernández, 2010).

Como ciencia jurídica, universal y general, el derecho de la información limita a los fenómenos informativos y les ofrece una específica perspectiva jurídica capaz de ordenar la actividad informativa, las situaciones y las relaciones jurídico - informativas y sus diversos elementos, al servicio del derecho a la información (M. Aguirre, 2003).

El acceso a la información posee dos vertientes, el derecho a comunicar $y$ el derecho a recibir información.

En su vertiente activa de comunicar información, comprende el derecho del emisor a comunicar o no la información; mientras que en la vertiente pasiva, esto es la de recibir información, se concreta al obtenerla de manera libre y veraz.

El derecho a recibir información es un presupuesto muy importante en el sentido de que el ciudadano pueda actuar responsablemente, permitiéndole formar 
libremente sus opiniones y participar en los asuntos públicos. Al respecto se sostiene que la opinión pública sólo puede constituirse a partir de individuos informados, es decir, titulares en ejercicio del derecho a recibir información (Pérez-Royo, 1999).

El derecho a recibir información sería vacío sin receptor, ya que no hay comunicación cuando el mensaje no tiene quien lo reciba, cuya inclusión en las normativas legales se justifica con el propósito de ampliar al máximo el conjunto de los legitimados para impugnar cualquier perturbación de la libre comunicación.

No debe confundirse el derecho de la información con el derecho a la información. La razón de ser del derecho de la información lo constituye el derecho a la información (Escobar-de-la-Serna, 1994). El derecho de la información tiene como objetivos hacer realizable el derecho a la información, el derecho a informar y a estar informado, el derecho a expresar ideas y a recibirlas (M. Fernández, 1990).

El derecho a la información es la finalidad del derecho de la información, contiene informaciones y opiniones, mismas que comprenden el conjunto de hechos, noticias, opiniones, ideas y mensajes que deben estar a disposición de la población para garantizar una opinión libre y plural, así como de procurar el sentido de participación en los asuntos públicos. Para la realización de este derecho es indispensable el ejercicio de las facultades de investigar, recibir y divulgar información (Hernández, 2010).

Según Escobar de la Serna (1994) el derecho a la información es la garantía que toda persona posee a investigar (el derecho a investigar incluye las facultades de acceso a los archivos, registros y documentos públicos y la decisión del medio por el que se vaya a leer, a escuchar o a contemplar), a informar (el derecho a informar incluye las libertades de expresión y de imprenta, y el de constitución de sociedades y empresas informativas) y ser informado (el derecho a ser informado incluye las facultades de recibir información objetiva y oportuna, la cual debe ser completa y con carácter universal, sin exclusión de personas).

Esta información abarca varios procedimientos, como su acopio, almacenamiento, difusión, etc., como puede ser de varios tipos, hechos, noticias, datos, opiniones, ideas y tener varias funciones (LópezAyllón, 2011).

Además de aquellos casos en los que contar con información es una precondición para el ejercicio de otros derechos, hay situaciones en las que el objeto central de la solicitud es la información en sí misma. En estos casos, el acceso a la información es entendido como un derecho autónomo y no como un derecho instrumental, pues es la obtención de los datos lo que satisface de manera directa y automática algún derecho.

En estas situaciones la esencia de las actividades es propiamente la búsqueda de la información. Este es el caso de la investigación, tanto científica como académica, actividades que requieren acceder a información para ser ejecutadas.

En este escenario, la obligación positiva del Estado de permitir el acceso a los archivos (el sentido común indica que "no se puede acceder a ninguna información si no existen verdaderos archivos, entendido como el recinto en el que se organizan técnicamente los documentos" (L. Ramos y Villar, 2013), sin embargo, en la realidad habrá que enfrentarse a la búsqueda de información en depósitos de documentos con poca posibilidad de recuperación), puede ser indispensable para desarrollar una investigación, actividad que tiene dos dimensiones.

Por una parte, la que es de carácter social, en donde se salvaguarda también el derecho colectivo a recibir el resultado de las investigaciones y que está basada incluso, en el derecho al desarrollo (Morales, 2011) y por otra parte, la que está vinculada con el ejercicio de un derecho individual, como lo es la libertad de profesión como la del investigador académico.

Otro término utilizado cuando se habla del derecho de acceso es la libertad de información. El objetivo que se consigue con esta libertad es la noticia, entendiéndose por tal los hechos verdaderos que puedan encerrar trascendencia pública (Escobar-de-laSerna, 1994); cuando se hace referencia a la comunicación informativa, de lo que se está hablando es del derecho a la información activa, a partir del derecho a comunicar libremente información veraz; es la realización del ejercicio propiamente dicho del derecho y la libertad de información.

\section{El acceso a la información pública como derecho fundamental}

Los derechos fundamentales pertenecen al individuo o al grupo, a la persona o a la asociación en que los hombres se inserten, pero a diferencia de los derechos del ámbito privado, no comportan solamente beneficios para el titular del derecho; suponen ventajas adicionales para el conjunto de los hombres y también para la sociedad y para el Estado (PecesBarba, 2014).

Los titulares de estos derechos son los seres humanos; la finalidad de los derechos fundamentales es impedir los abusos del poder por parte de los titulares de las funciones estatales (Bastida y otros, 2004). 
Sobre ellos, dada la normativa de las Constituciones en torno al catálogo de derechos fundamentales, son muchas las dificultades para concebirlos como una verdadera ética, pues estos derechos encarnan más bien un consenso jurídico acerca de lo que podemos hacer, más que un consenso moral acerca de lo que debemos hacer (Prieto, 2001), sumándole a este hecho, la paradoja de elegir, directa o indirectamente, quiénes están llamados a decidir, vía legislación, cuáles son $\mathrm{o}$ no son derechos fundamentales .

La fundamentalidad es definida por el lugar que los derechos ocupan en la jerarquía normativa Constitucional de los Estados; el concepto de derecho fundamental depende de la determinación del derecho que los contiene, es decir, los criterios de identificación de los derechos fundamentales se encuentran en el propio ordenamiento jurídico Constitucional (Barranco, 2001).

El derecho de acceso a la información pública debe ser considerado como un derecho fundamental (Piñar, 2014) considerándolo como la facultad que tiene todo ciudadano de acceder a todo tipo de información, en poder de entidades públicas y privadas que ejerzan funciones públicas o reciban fondos del Estado, con la consecuente obligación estatal de instrumentar un sistema administrativo que facilite a cualquiera la identificación y el acceso a la información solicitada (Díaz, 2009); este derecho fundamental permite la prerrogativa de acceder a los datos, registros y todo tipo de informaciones en poder de las entidades que ejercen gasto público o cumplan funciones de autoridad, con las excepciones taxativas que pueda establecer la ley (Villanueva, 2003).

Por lo que se puede determinar que el derecho de acceso tiene un doble enfoque. Por un lado, existe el derecho de cualquier ciudadano a acceder a la información pública que quiera conocer y por otro lado, existe el deber del Estado de dar a conocer a la ciudadanía sus decisiones de manera completa, en función de la lógica democrática.

El derecho fundamental de acceso a la información pública abarca tanto al acceso a los documentos y a los archivos, como a la información pública, es decir, a toda aquella información producida o que obra en poder de la Administración Pública. Es necesario por lo tanto, que se establezca la más amplia aplicación posible del derecho de acceso a la información que esté en posesión, custodia o control de cualquier autoridad pública, fundamentándose en el principio de máxima publicidad, de tal manera que cualquier información en manos de instituciones públicas sea completa, oportuna y accesible, sujeta a un claro y preciso régimen de excepciones (Gil-leiva y Moya, 2011).
El reconocimiento del derecho de acceso a la información pública y su efectiva concreción es un parámetro de suma importancia al momento de evaluar el grado de transparencia del que goza una sociedad (Basterra, 2010). Es impensable hablar de control en la actividad administrativa y en los actos de los gobernantes, si como contrapartida no se garantiza el acceso al público para tomar conocimiento de los mismos.

El derecho de acceso a la información pública se trata de una prerrogativa fundamental que se constituye en una herramienta legal para alcanzar la publicidad de los actos del Estado, pero también actúa como medio de fiscalización y participación efectiva de todos los sectores de la sociedad, sin discriminación, lo que habilita la intervención activa e informada sobre el diseño de políticas y medidas públicas que afectan directamente a la población.

\section{El derecho de acceso a la información pública}

El derecho de acceso a la información pública es una parte especial del derecho a la información; es el derecho que tienen todos los individuos para acceder a las fuentes de información pública del Estado con el fin de investigar, recibir y difundir información sobre los actos que se generan en virtud de sus facultades constitucionales y legales (Hernández, 2010); sus objetivos suelen ser, entre otros, conocer el manejo de los recursos públicos, los programas y acciones de los poderes públicos, las políticas públicas, los resultados obtenidos de los programas públicos y las razones que se consideraron para determinar ciertas acciones.

El acceso a la información pública es un instrumento para el control democrático de las instituciones públicas, que se concibe desde una perspectiva funcional, como un derecho vinculado directamente con la garantía de una opinión pública libre, que se conecta a su vez y estrechamente con la existencia de un sistema democrático (Díez, 2002). Un ciudadano bien informado puede vigilar e involucrarse en el destino y manejo de los recursos públicos, así como participar en los asuntos nacionales, regionales y locales, y formarse de esta manera una opinión meditada.

El derecho a la participación política implica el hecho de que, además de deliberar libre e informadamente sobre asuntos públicos (derechos civiles), la ciudadanía podrá participar directamente en la conducción de dichos asuntos (derechos políticos).

La participación en la gestión de los asuntos públicos, la participación en elecciones y el acceso a las funciones públicas, requieren de información 
suficiente. Todos los mecanismos de la democracia participativa serían completamente vacuos y hasta peligrosos si desde el propio Estado no se asegurara un efectivo acceso a la información que permita formar, a nivel de cada ciudadano, un juicio informado acerca de aquellas cuestiones sobre las que permanentemente se le solicite su opinión.

El derecho de acceso a la información pública se desarrolla como un derecho fundamental de múltiples dimensiones; posee un valor reformador especial para la construcción de una ciudadanía activa y participativa, que busque incidir en el quehacer público; representa la más efectiva, eficiente y legítima forma en la que se puede comprobar que la actuación de los servidores públicos se apega a su mandato y que los recursos públicos son destinados a organismos públicos que ofrecen resultados ciertos y tangibles (Pulido, 2006).

El derecho de acceso a la información pública es aquél que reconoce, por una parte, el derecho ciudadano a conocer dicha información y por otra parte, la obligación del Estado de permitir su acceso, resultando irrelevante preguntar a la ciudadanía los motivos para solicitar información (Moraga, 2008).

El derecho de acceso a la información pública es considerado como el derecho de conocer la información de carácter público que se genera o que está en poder de los poderes públicos, y de todos aquellos organismos que utilizan o se benefician con recursos públicos que provienen del Estado (Carbonell, 2013); es la prerrogativa de una persona para acceder a datos y registros de todo tipo de información en poder de los organismos públicos y entidades privadas que reciban dinero público, con las excepciones que establezca la ley en cualquier sociedad democrática (Villanueva, 2003).

El acceso a la información pública implica la implementación de prácticas sencillas y actuaciones que no inhiban el interés ciudadano de conocer la información pública, evitando desplazamientos físicos innecesarios, ponderando los gastos que implica cumplir con un procedimiento e implementando medios alternativos de difusión (Pulido, 2006).

Este derecho tiene dos tipos de manifestaciones:

- La primera manifestación se produce cuando el ciudadano tiene acceso a ciertos datos que le afectan directamente, puesto que se trata de documentos de un proceso judicial o administrativo, en el que el interesado sea parte.

- La segunda manifestación se produce cuando el ciudadano tiene acceso a documentos que no le afectan directamente, puesto que no es parte directa del proceso que contiene la información. En este último supuesto, tampoco es necesario justificar ningún tipo de interés jurídico para poder tener acceso a dicha información.

La información pública comprende documentos que pueden ser de distintas naturalezas, como políticos, informes de los organismos públicos, registros públicos, legislación y el resto de normativa pública, bases de datos de información científica, estadísticas, mapas y otros numerosos datos $y$ productos informativos producidos por el gobierno para propósitos públicos .

El derecho de acceso a la información pública incluye las libertades tradicionales de expresión e imprenta, y extiende su protección a la búsqueda, difusión y recepción de informaciones, opiniones o ideas por cualquier medio (López-Ayllón, 2011).

Los ciudadanos tendrán un verdadero ejercicio de acceso a los archivos y registros administrativos cuando éstos guarden la memoria de todos los actos de los poderes públicos derivados de sus facultades constitucionales y legales, cuando los poderes públicos tengan la obligación de promover y facilitar la participación de todos los ciudadanos en la vida política, económica, cultural y social, cuando los órganos de gobierno estén comprometidos con la transparencia y la publicidad de sus actos, cuando la Administración Pública sirva con objetividad a los intereses generales y actúe con eficacia (Hernández, 2010) con el objeto de informarse de las fuentes directas de los asuntos públicos de Gobierno. Sólo en este escenario, los ciudadanos y las personas en general estarán en posibilidades de participar en la vida política, en el debate público, en comunicar y recibir información.

\section{Sujetos y objetos del derecho de acceso a la información pública}

Los sujetos son las personas legitimadas por las normativas jurídicas para ejercer derechos o cumplir obligaciones. En el derecho de acceso a la información pública concurren dos sujetos: el sujeto activo y el sujeto pasivo.

El sujeto activo es el titular del derecho de acceso a la información pública, cuyo ejercicio en principio debe ser concedido a todas las personas, de tal manera que no debe restringirse por razones de ciudadanía o nacionalidad, ni debe solicitarse legitimación especial para el goce y ejercicio efectivo de este derecho. Esto debido a la gama de finalidades por las cuales una persona desearía hacer uso del derecho, como la pretensión de controlar o supervisar la actividad estatal, así como perseguir la protección de intereses públicos, ambientales, patrimoniales, culturales, de negocios, empresariales, licitaciones públicas o de intereses personales, como el ejercicio del derecho a la intimidad (Ares, 2014). 
Las reglas sobre la legitimación para el ejercicio de este derecho deben ser mínimas, donde el solicitante de la información no debe estar obligado a acreditar un interés jurídico, ni debe ser necesario motivar su solicitud (Martí, 2005).

Por otra parte, el sujeto pasivo es quien tiene a su cargo el deber de proporcionar la información solicitada. En un primer momento, se limitaba al sujeto pasivo al poder ejecutivo; luego se incluía además a los poderes legislativo y judicial; en la actualidad, doctrinalmente hablando, se incluye a todos los organismos del Estado, públicos y privados, que reciban dinero del erario nacional y que sin revestir necesariamente forma de entidad pública, puedan catalogarse como personas jurídicas de interés público, por haber sido creadas para satisfacer necesidades de interés general, por estar financiadas por la administración pública, porque sus órganos de gobierno estén compuestos por miembros de entidades de derecho público, o porque su gestión se encuentre sometida por una ley de control público.

La obligación de informar le comprende también con carácter general a los organismos autónomos, descentralizados, desconcentrados y a entidades privadas que manejen recursos públicos o que actúen colaborando con autoridades públicas, "son los organismos que ejercen funciones públicas los que detentan mejores medios materiales, técnicos y profesionales para ayudar a los ciudadanos, y a la inversa" (Ferreyra, 2013).

En cuanto al objeto del derecho de acceso a la información pública, algunas normas iniciales sobre este tema, incluyendo alguna de las analizadas en un apartado anterior, ordenaban que sólo podían ser objetos del derecho de acceso a la información pública, aquellos documentos contenidos en expedientes que correspondían a procedimientos terminados en la fecha de la solicitud (Vásquez, 2002), argumentación que no tuvo eco por ser restrictiva, ya que contrario a este hecho, el derecho de acceso a la información pública busca democratizar el actuar de los individuos de una sociedad, por lo que se considera que la información le pertenece al ciudadano y que es administrada por el Estado, ciudadano que al obtener directamente la información, le permite la posibilidad de llevar a cabo decisiones informadas en su vida cotidiana.

El objeto principal del derecho al acceso a la información pública es la información, que es conocida por las personas, cuyo flujo debe convertirse en la herramienta para la acertada toma de decisiones, que a su vez permitirá la interrelación de distintos derechos subsidiarios que lograrán al final mejorar la calidad de vida de una sociedad (Villanueva, 2003).
La información como bien jurídico protegido, permite que los individuos tengan acceso a las políticas mediante las cuales el gobierno toma decisiones que los afectan directamente respecto a proyectos de salud, educación, vivienda e infraestructura y las razones por las que se sustentan tales decisiones (Neuman, 2002).

El objeto del derecho de acceso es la información contenida en las administraciones públicas, en forma tal que resulte clara e inteligible, en tanto que los archivos, registros y documentos son los medios instrumentales que posibilitan el ejercicio de tal derecho (Álvarez, 1979); información que debe ser protegida por los representantes que forman parte de la estructura del poder público, que han accedido al gobierno porque son elegidos con el sufragio de todos los ciudadanos (García-de-Enterría, 2006) y que ejercen sus funciones con el uso de los recursos aportados por toda una sociedad.

\section{Necesidad de una ley que regule el derecho de acceso, garantizándolo mediante una autoridad independiente}

La administración tradicional se ha caracterizado por la imposición de una regla general de secreto, como por una amplia discrecionalidad para decidir acerca de la comunicación a la ciudadanía de los documentos e información administrativos, sustentándose en la ausencia de una regla de comportamiento general y en el deber estatutario de discreción de los empleados públicos, reforzado por una arraigada cultura del secreto como instrumento de poder (Velasco, 2014).

En cambio, el derecho de acceso a la información es un requisito de participación ciudadana democrática dentro de un Estado, que no debe sucumbir a una dinámica burocrática. En los Estados donde los trámites burocráticos son excesivos, los ciudadanos tienen dificultad para conocer la totalidad de la información que les permita una auténtica participación democrática en la política estatal.

En esta clase de Estados, ni siquiera las propias instituciones públicas son con frecuencia conscientes de la existencia de la información que ellos mismos resguardan, todavía menos de la perteneciente a otras instituciones públicas y generalizadamente afecta hasta al poder legislativo, que ve restadas sus potestades investigadoras y fiscalizadoras (Efraín Pérez y Makowiak, 2004).

Debido al significado rupturista que representa el reconocimiento de este derecho, pues supone invertir las reglas de la comunicación de la información y habiendo determinado en un apartado anterior de la necesaria fundamentalidad y origen constitucional del derecho de acceso a la información pública, es 
necesario que su ordenación sea expresa mediante una ley que garantice un contenido exhaustivo.

La norma que pretenda implantar un derecho de acceso a la información pública debe poseer rango formal de ley, por varias razones:

- Porque desde la perspectiva de los ciudadanos, tal norma disciplina un derecho de las relaciones entre ellos y las administraciones públicas, un derecho que debe tener la naturaleza de derecho fundamental, como ya se indicó en un apartado anterior.

- Porque desde la perspectiva de la Administración, el derecho de acceso a la información pública constituye una pieza fundamental para la concreción del principio de transparencia administrativa, llamado a constituir uno de los ejes del sistema administrativo.

- $\quad$ Porque al ser regulado mediante una ley, ésta le ofrecerá mayor legitimación democrática.

Por otro lado, no hay que olvidar que la Ley por sí sola no es suficiente para implantar el derecho de acceso a la información pública. La aprobación de una Ley de acceso a la información pública por muy bien intencionada y progresiva que sea, no es en sí misma suficiente para generar la inversión en las prácticas y usos administrativos que requiere el derecho de acceso a la información, sino que la Ley debe concebirse como un instrumento imprescindible de implementación de una verdadera política pública de transparencia, que comprenderá otras medidas complementarias y una auténtica voluntad política de impulso del principio de este principio, cuya "definición se encuentra estrechamente relacionada con la confianza" (Vera, 2015).

El derecho de acceso a la información pública es un derecho extraordinariamente frágil, pues existen formas de vulnerarlo, empezando por el simple silencio frente a las peticiones de comunicación. Debe así subrayarse, que el derecho de acceso a la información pública precisa de un especial cuidado para garantizar su efectividad. Y a tal efecto, la experiencia comparada ha demostrado el papel esencial en los sistemas de transparencia que están desempeñando las instituciones administrativas encargadas de velar por la aplicación del derecho, lo que se analizará en un apartado posterior.

En todo caso, es evidente que la implantación de una política pública de transparencia debe empezar por el propio proceso de elaboración de la Ley, que deberá desarrollarse mediante un proceso público y participativo.

Sobre la necesidad de una autoridad independiente para garantizar la aplicación de la ley de acceso a la información pública, en algunos modelos se ha previsto la formulación de una queja ante el Defensor del Pueblo o figura similar, que es seleccionado regularmente por el Poder Legislativo. Sin embargo, la relación cercana de este órgano con la Asamblea Legislativa plantea dudas, acerca del criterio de atribuir a éste comisionado parlamentario facultades coercitivas frente a la Administración.

En cambio, se ha presentado una interesante experiencia en la constitución de Comisiones de Acceso a los Documentos Administrativos, como órganos dotados de autonomía funcional $y$ configurados como instituciones con personalidad jurídica propia e independiente, elegidos por concursos públicos de merecimiento y oposición. Este tipo de organismos deben estar dotados de autonomía funcional e integrados por expertos que garanticen la competencia de sus decisiones, lo que representa una ventaja adicional que puede ser decisiva para el éxito del dispositivo legal de acceso (S. Fernández, 2008).

En última instancia, la función de la garantía jurídica del derecho de acceso a la información pública debe corresponder a los órganos judiciales ordinarios competentes; camino legal que posee como desventaja, el coste económico del proceso, que supone un serio obstáculo para acudir a la tutela judicial.

De aquí la conveniencia de que el sistema de acceso a la información pública esté auxiliado por un órgano dotado de autoridad suficiente para elaborar un cuerpo doctrinal, susceptible de cumplir una función de orientación para la Administración y coadyuvar a los mismos tribunales en la difícil y casuística aplicación de la Ley.

En general, la autoridad o empleado público carece tanto de un especial afán por facilitar la información, como por ocultarla. Sin embargo, este servidor público al que se solicita el acceso a la información se ve empujado a una encrucijada, pues es consciente de que si comunica indebidamente información confidencial puede comprometer su responsabilidad personal, incluso de carácter civil, administrativo y penal, por revelación de secretos. Y de aquí también la importancia de contar con un cuerpo de precedentes elaborado por un órgano especializado, que permita descargar del funcionario de esa eventual responsabilidad, por los efectos causados por una comunicación indebida.

\section{Referencias}

Aguirre, Marisa (2003). "El derecho de la información como ciencia". En: Bel, Ignacio; Corredoira, Loreto (eds.). Derecho de la información. Barcelona: Editorial Ariel, p. 47-64. 
Álvarez, Manuel (1979). El derecho de acceso a los documentos administrativos. Documentación Administrativa, núm. 183, p. 103-134.

Ares, Valle (2014). "Los ámbitos subjetivo y objetivo de la transparencia de la actividad pública". En: Moretón, Arancha (coord.). Revista Jurídica de Castilla y León: transparencia, acceso a la información pública y buen gobierno, análisis de la cuestión tras la Ley 19/2013, núm. 33, p. 1-27.

Barranco, María (2001). El concepto republicano de libertad y el modelo constitucional de derechos fundamentales. Anuario de Filosofía del Derecho, núm. 18, p. 205-226.

Basterra, Marcela (2009). Derecho fundamental de acceso a la información pública en Argentina. Biblioteca Jurídica Virtual del Instituto de Investigaciones Jurídicas de la UNAM, núm. 13, p. 1-28. $<$ http://www.juridicas.unam.mx/publica/libre $\mathrm{v} / \mathrm{rev} / \mathrm{decoin} /$ cont/13/art/art1.pdf $>$. [Consulta: 22/11/2013].

Bastida, Francisco; Villaverde, Ignacio; Requejo, Paloma; Presno, Miguel; Aláez, Benito; Sarasola, Ignacio (2004). Teoría general de los derechos fundamentales en la Constitución española de 1978. Madrid: Editorial Tecnos.

Carbonell, Miguel (2013). Derechos fundamentales y democracia. México: Instituto Federal Electoral.

Díaz, Santiago (2009). El derecho de acceso a la información pública: situación actual y propuestas para una ley. Lecciones y Ensayos, núm. 86, p. 151-185.

Díez, Laura (1999). Derecho a la información y retransmisiones deportivas. Quaderns del CAC, núm. 6, p. 9-16.

(2002). La relevancia pública en el derecho a la información. Revista Española de Derecho Constitucional, núm. 66, p. 213238.

(2007). La llibertat d'expressió i els seus límits. Quaderns del CAC, núm. 27, p. 95101.

Escobar-de-la-Serna, Luis (1994). Manual de derecho de la información. Madrid: Editorial Dykinson.
Fernández, Manuel (1990). Nuevas tendencias de la información. Comunicación y Sociedad: Revista de la Facultad de Comunicación, vol. 3, núm. 1, p. 209-225.

Fernández, Severiano (2008). "Diez anotaciones para una ley española de acceso a la información pública". En: Sánchez-de-Diego, Manuel (coord.). El papel del derecho de la información en la sociedad del conocimiento: el derecho de acceso a la información pública. Madrid: CERSA, p. 122-151.

Ferreyra, Leandro (2013). Acceso a la información: hacia la democratización de la administración pública. Lecciones y Ensayos, núm. 91, p. $117-134$

García-de-Enterría, Eduardo (2006). La democracia y el lugar de la ley. Anuario de la Facultad de Derecho de la Universidad Autónoma de Madrid, núm. 1, p. 79-95.

Gil-leiva, Isodoro; Moya, Gregorio (2011). El acceso a la información pública: estudio de casos de Brasil, España y Portugal. Informação \& Sociedade: Estudos, vol. 21, núm. 1, p. 7389.

Hernández, Alfonso (2010). "El acceso a la información pública: evolución $\mathrm{y}$ consolidación de un derecho fundamental de nueva generación". Directora: María Gómez Fernández. Tesis de doctorado. Madrid: Universidad Carlos III.

López-Ayllón, Sergio (2011). La opacidad de la transparencia. Política Digital, núm. 65, p. 24-27.

Martí, Luz (2005). "El derecho de acceso a la información en México". En: Democracia y derecho a la información. Director: Salvador Valencia Carmona. Tesis de doctorado. Xalapa: Universidad Veracruzana, p. 301456.

Moraga, Eva (2008). "Sobre la necesidad de una ley española de acceso a la información pública". En: Sánchez-de-Diego, Manuel (coord.). El papel del derecho de la información en la sociedad del conocimiento: el derecho de acceso a la información pública. Madrid: CERSA, p. 152-157.

Morales, Estela (2011). Derecho a la información, bien público y bien privado: acceso 
comunitario y acceso individual. México: UNAM.

Neuman, Laura (2002). Acces to information, a key to democracy. The Carter Center. Atlanta: The Carter Center.

Peces-Barba, Gregorio (2014). Historia de los derechos fundamentales. Madrid: Editorial Dykinson.

Pérez, Efraín; Makowiak, Jéssica (2004). El derecho de acceso a la información en Europa y América Latina: un enfoque constitucional. Medio Ambiente \& Derecho: Revista Electrónica de Derecho Ambiental, núm. 10. $<$ http://huespedes.cica.es/gimadus/>.

[Consulta: 29/09/2013].

Pérez-Royo, Javier (1999). Derecho a la información. Boletín de la Anabad, vol. 49, núm. 3/4, p. 19-34.

Piñar, José (2014). Transparencia y derecho de acceso a la información pública. Algunas reflexiones en torno al derecho de acceso en la ley 19/2013, de transparencia, acceso a la información y buen gobierno. Revista Catalana de Dret Públic, número 49, p. 1-19.

Prieto, Luis (2001). Neoconstitucionalismo y ponderación judicial. Anuario de la Facultad de Derecho de la UAM, núm. 5, p. 201-227.

Pulido, Miguel (2006). El acceso a la información es un derecho humano: propuesta para un estándar de acceso a la información de organismos públicos de derechos humanos. México: Mono Comunicación.

Ramos, Lourdes; Villar, Alejandra (2013). The access to public information and the archives in Uruguay. Revista Palabra Clave de la UNLP, vol. 3 , núm. 1, p. 45-51.

Vásquez, Jorge (2002). El derecho de acceso a archivos y registros públicos, $<$ http://www.redes-

cepalcala.org/inspector/DERECHO/ARTICU LOS/ ARCHIVOS-REGISTROS.htm>. [Consulta: 19/09/2013].

Velasco, Clara (2013). Análisis en clave competencial del proyecto de ley estatal sobre transparencia, acceso a la información pública y buen gobierno. Revista D'estudis Autonòmics i Federals, núm. 17, p. 279-328.
Vera, Martín (2015). El acceso a la información pública y su impacto en la corrupción: el caso de México. Gestión y Análisis de Políticas Públicas, núm. 13, p. 1-13.

Villanueva, Ernesto (2003). Derecho de acceso a la información pública en Latinoamérica. México: Instituto de Investigaciones Jurídicas de la UNAM. 